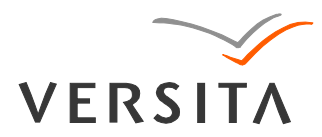

GEOCHRONOMETRIA 41(1) 2014: 57-64

DOI $10.2478 / \mathrm{s} 13386-013-0138-1$

Available online at

www.springerlink.com

\title{
EXAMINING QUARTZ OSL AGE UNDERESTIMATION FOR LOESS SAMPLES FROM LUOCHUAN IN THE CHINESE LOESS PLATEAU
}

\author{
ZHONGPING LAI ${ }^{1}$ and ANCHUAN FAN ${ }^{2,3}$ \\ ${ }^{1}$ Luminescence Dating Group, CAS Key Laboratory Of Salt Lake Resources and Chemistry, Qinghai Institute of Salt Lakes, Chinese \\ Academy of Sciences, Xining 810008, PR China \\ ${ }^{2}$ Dept of History of Science and Technology and Archaeometry University of Science and Technology of China (USTC), \\ Hefei 230026, PR China \\ ${ }^{3}$ USTC Archaeometry Laboratory, University of Science and Technology of China, Hefei 230026, PR China
}

Received 29 January 2013

Accepted 22 August 2013

\begin{abstract}
When using quartz OSL to date loess samples from the Chinese Loess Plateau, it has been reported that the agreement between OSL ages and the independent ages is limited to the samples younger than $\sim 70 \mathrm{ka}$ with a corresponding $\mathrm{D}_{\mathrm{e}}$ of $\sim 230 \mathrm{~Gy}$, and a sample with an expected age of $780 \mathrm{ka}$ was dated to $107 \mathrm{ka}$, corresponding to $403 \mathrm{~Gy}$. The growth curves of these samples do not saturate at doses of $700 \mathrm{~Gy}$, and a linear growth part was observed for doses higher than $200 \mathrm{~Gy}$. However, the maximum measured age of $\sim 100 \mathrm{ka}$ imply that the $\mathrm{D}_{\mathrm{e}}$ determined using this linear part of a growth curve could be problematic, or that the quartz OSL signal is not as stable as previously thought and has a barrier age of $\sim 100 \mathrm{ka}$. In the current study, we examine the reasons for the age underestimation. We examined the shape of growth curves, anomalous fading, thermal stability, etc. The results show that, for the loess samples examined, quartz OSL does not fade anomalously, and the barrier age of $\sim 100 \mathrm{ka}$ is due to the fact that the OSL signals are less thermally stable, the lifetime of $0.311 \mathrm{Ma}$ at $20^{\circ} \mathrm{C}$ obtained is much smaller than those for quartz samples from other regions such as Australia ( 100 Ma).
\end{abstract}

Keywords: quartz OSL, age underestimation, Chinese loess, signal stability.

\section{INTRODUCTION}

As a dosimeter in luminescence dating, quartz is much preferred over feldspars due to its non-anomalousfading signal and the much simpler trap or recombination center mechanism. However, the quartz signal saturates at a lower dose (see review by Wintle and Murray, 2006, and references therein). Recently, a growing body of data shows that the quartz OSL SAR (Single Aliquot Regenerative dose protocol) growth curve has a linear growth part in the high dose range of $c a$. 200-1000 Gy, which

Corresponding author: Z. P. Lai

e-mail: zplai@isl.ac.cn could allow the $\mathrm{D}_{\mathrm{e}}$ determination up to $>400$ Gy (Watanuki et al., 2003, 2005; Buylaert et al., 2008; Lai, 2010; Lowick et al., 2010; Lowick and Preusser, 2011). When using quartz OSL SAR protocol to date loess samples from Luochuan section, a standard loess section in the Chinese Loess Plateau (CLP) with a well-defined independent chronology based on astronomical tuning ( $\mathrm{Lu}$ et al., 1999), it has been reported that the agreement between OSL ages and the independent ages is limited to $70 \mathrm{ka}$ with a corresponding $\mathrm{D}_{\mathrm{e}}$ of $c a .230 \mathrm{~Gy}$, and that the measured age was only $107 \mathrm{ka}$ (with a corresponding age of 403 Gy) for a sample collected just below the B/M boundary with an expected age of $780 \mathrm{ka}$ (Lai, 2010). 
Underestimation observations have also been made by Buylaert et al. (2008), Qin and Zhou (2009), and Chapot et al. (2012) for Chinese loess. These seem to imply that the $\mathrm{D}_{\mathrm{e}}$ determined using this linear part of a growth curve could be problematic, or that the quartz OSL signal is not as stable as previously thought. Lu et al. (2007), however, reported the OSL dating of the loess samples $<130 \mathrm{ka}$ from the Luochuan section using a quartz OSLMAR method. Their OSL ages obtained are broadly consistent with the expected ages, and the age underestimation is not apparent for samples from the L1 unit.

For the linear part of the growth curve at high doses, it is possible that the trap/luminescence recombination center, which is assumed to be responsible for the linear growth part, does not exist in nature (Lai, 2010), and is created by laboratory irradiation only, which cannot be removed by the preheat (Lai, 2010). When investigating quartz OSL dose-response curves at high doses, Lowick et al. (2010) proposed that a likely explanation is that for the change in OSL response at high doses is a change in competition for electrons between the UV recombination centers whose emission is seen through the detection windows and recombination centers that do not emit in this spectral region (or are non-radiative).

The lower thermal stability of luminescence signals could lead to age underestimation, which has been shown for feldspars (Wintle, 1973; Debenham, 1985; Lamothe and Auclair, 1999). Previous studies showed that the quartz OSL signal is dominated by a stable signal with a lifetime of $850 \mathrm{Ma}$ at $20^{\circ} \mathrm{C}$, confirming its suitability for dating (Murray and Wintle, 1999). However, it has been reported that the OSL of some quartz showed much lower stability which could lead to age underestimation by more than a factor of 10 (Bonde et al., 2001; Choi et al., 2003; $\mathrm{Li}$ and Li, 2006; Tsukamoto et al., 2007; Fan et al., 2011). In particular, Fan et al. (2011) dated samples from Salawusu in the $\mathrm{Mu}$ Us desert in northern China, which was situated to the north of the CLP and regarded as one of the dust sources for the loess deposits in the CLP. Based on the single-grain pulse annealing results they demonstrated that, for some of the quartz grains, the fast component is thermally unstable. They tried to isolate those grains with stable OSL for age calculation and the resultant ages are consistent with independent control.

In this study, we investigated the luminescence properties of quartz grains from loess samples from the Luochuan section, and try to explain the quartz OSL age underestimation of loess samples.

\section{SAMPLES USED}

Four samples (LC12, LC22, LC30, and LM/9) were selected to represent the loess samples. The samples used are 45-63 $\mu \mathrm{m}$ fractions of quartz grains from Luochuan section in the CLP in northern China, and have been OSL dated by Lai (2010). Medium aliquots ( 3 $\mathrm{mm}$ in diameter) were used in all measurements. The relevant sample information is summarized in Table 1, including the dose rate and expected age data. The section is a classical standard section due to its clear loess-palaeosol alternations reflecting the glacial-interglacial cycles (Kukla and An, 1989). A well-defined chronology based on astro-

Table 1. Sample information for Luochuan loess (data from Lai, 2010). A well-defined chronology based on astronomic tuning has been established for this section (Lu et al., 1999), which is taken as an independent age control, and the expected ages for samples between loess/soil boundaries have been obtained using interpolation with an error of $10 \%$.

\begin{tabular}{|c|c|c|c|c|c|c|}
\hline $\begin{array}{l}\text { Sample } \\
\text { ID }\end{array}$ & $\begin{array}{c}\text { Depth } \\
(\mathrm{m})\end{array}$ & $\begin{array}{c}\text { Dose Rate } \\
\text { (Gy/ka) }\end{array}$ & $\begin{array}{c}\text { OSL De } \\
\text { (Gy) }\end{array}$ & $\begin{array}{l}\text { OSL Age } \\
\text { (ka) }\end{array}$ & $\begin{array}{c}\text { Expected } \\
\text { Age (ka) }\end{array}$ & $\begin{array}{l}\text { Position } \\
\text { in section }\end{array}$ \\
\hline$\overline{\mathrm{LC} 4}$ & 2.5 & $3.14 \pm 0.21$ & $75 \pm 2$ & $24.0 \pm 1.7$ & 25.0 & $\mathrm{~L} 1$ \\
\hline LC5 & 2.8 & $3.13 \pm 0.21$ & $83 \pm 4$ & $26.5 \pm 2.2$ & 27.0 & $\mathrm{~L} 1$ \\
\hline LC7 & 3.4 & $3.45 \pm 0.23$ & $111 \pm 5$ & $32.2 \pm 2.6$ & 31.1 & $\mathrm{~L} 1$ \\
\hline LC9 & 4 & $3.20 \pm 0.22$ & $121 \pm 3$ & $37.8 \pm 2.8$ & 35.2 & $\mathrm{~L} 1$ \\
\hline $\mathrm{LC12}$ & 4.8 & $3.24 \pm 0.22$ & $135 \pm 5$ & $41.7 \pm 3.1$ & 40.7 & $\mathrm{~L} 1$ \\
\hline LC14 & 5.4 & $3.35 \pm 0.23$ & $138 \pm 5$ & $41.2 \pm 3.2$ & 44.7 & L1 \\
\hline LC16 & 6 & $3.36 \pm 0.23$ & $174 \pm 4$ & $51.9 \pm 3.7$ & 48.8 & $\mathrm{~L} 1$ \\
\hline LC35 & 6.9 & $3.24 \pm 0.22$ & $182 \pm 5$ & $56.2 \pm 4.2$ & 54.9 & $\mathrm{~L} 1$ \\
\hline LC33 & 7.6 & $3.15 \pm 0.22$ & $200 \pm 10$ & $63.5 \pm 5.3$ & 59.7 & L1 \\
\hline LC30 & 8.5 & $3.17 \pm 0.25$ & $195 \pm 6$ & $61.5 \pm 5.2$ & 65.8 & L1 \\
\hline LC29 & 8.8 & $3.29 \pm 0.26$ & $213 \pm 10$ & $64.6 \pm 5.9$ & 67.9 & L1 \\
\hline LC28 & 9.1 & $3.27 \pm 0.26$ & $216 \pm 13$ & $66.0 \pm 6.6$ & 73.0 & L1 \\
\hline LC27 & 9.4 & $3.15 \pm 0.26$ & $231 \pm 12$ & $73.2 \pm 6.4$ & 80.3 & $\mathrm{~S} 1(0.3 \mathrm{~m}$ below L1) \\
\hline LC26 & 10 & $3.53 \pm 0.27$ & $283 \pm 12$ & $80.3 \pm 7.0$ & 94.9 & S1 \\
\hline $\mathrm{LC} 25$ & 10.3 & $3.49 \pm 0.27$ & $289 \pm 10$ & $82.7 \pm 7.0$ & 102.2 & S1 \\
\hline LC24 & 10.6 & $3.58 \pm 0.28$ & $313 \pm 11$ & $87.4 \pm 7.5$ & 109.5 & S1 \\
\hline LC23 & 10.9 & $3.45 \pm 0.27$ & $308 \pm 13$ & $89.5 \pm 8.0$ & 116.8 & S1 \\
\hline LC38 & 11.2 & $3.47 \pm 0.27$ & $296 \pm 9$ & $85.3 \pm 7.1$ & 124.1 & S1 \\
\hline LC22 & 11.5 & $3.32 \pm 0.27$ & $315 \pm 11$ & $94.9 \pm 8.3$ & 131.4 & $\mathrm{~S} 1$ (0.3 $\mathrm{m}$ above L2) \\
\hline L9/M & c. 60 & $3.77 \pm 0.28$ & $403 \pm 25$ & $107 \pm 10$ & 780.0 & L9 (just below B/M) \\
\hline
\end{tabular}


nomic tuning has been established for this section ( $\mathrm{Lu}$ et al., 1999), which is taken as independent age control, and the expected ages for samples between loess/soil boundaries have been obtained using interpolation with an error of $10 \%$.

\section{MEASUREMENT INSTRUMENTS}

A Risø automated TL/OSL system was used for all measurements. The OSL signals were measured by a photomultiplier with U-340 filters under the stimulation of blue light-emitting diodes $(470 \pm 30 \mathrm{~nm})$. Beta irradiation was performed using the ${ }^{90} \mathrm{Sr} /{ }^{90} \mathrm{Y}$ beta source within the Risø system.

\section{EXPERIMENT RESULTS AND DISCUSSIONS}

\section{Growth curves}

The quartz OSL growth curve of the Luochuan samples up to a dose of 700 Gy has been constructed by Lai (2010, in his Fig. 5) using a SAR protocol, with a preheat at $260^{\circ} \mathrm{C}$ for $10 \mathrm{~s}$ and with the test dose receiving a cutheat of $220^{\circ} \mathrm{C}$ for $10 \mathrm{~s}$, and OSL of the first $0.8 \mathrm{~s}$ stimulation (background of the last $5 \mathrm{~s}$ was subtracted) was integrated for growth curve construction. The growth curve was constructed using four aliquots of sample L9/Ma and could be well-fitted using a single exponential plus linear function:

$Y=8.55 \cdot(1-\exp (-X / 128.3))+0.0062 X$

where $\mathrm{D}_{0}$ is 128.3 (Gy) (Lai, 2010). Assuming a maximum $D_{e}$ value can be determined up to $2 D_{o}$ (Wintle and Murray, 2006), $D_{e}$ values up to 256 Gy should be obtainable. Fig. 1 shows the comparison of the expected ages with the OSL ages for samples younger than $150 \mathrm{ka}$, not including the sample of $\mathrm{L} 9 / \mathrm{M}$. Samples older than $70 \mathrm{ka}$ are underestimated. L9/M, which has an expected age of $780 \mathrm{ka}$, gave an age of $107 \mathrm{ka}$.

It will be interesting to see the shape of the growth curve in nature. Chapot et al. (2012) have constructed a natural dose response curve for known-age samples from Luochuan section, but with only 5 samples within a dose range of $500 \mathrm{~Gy}$. Here we use 19 samples within a dose range of 450 Gy. For each sample listed in Table 1, the sensitivity corrected natural signals $\left(\mathrm{L}_{\mathrm{N}} / \mathrm{T}_{\mathrm{N}}\right)$ have been measured for four aliquots. In Fig. 2 the $\mathrm{X}$-axis is the

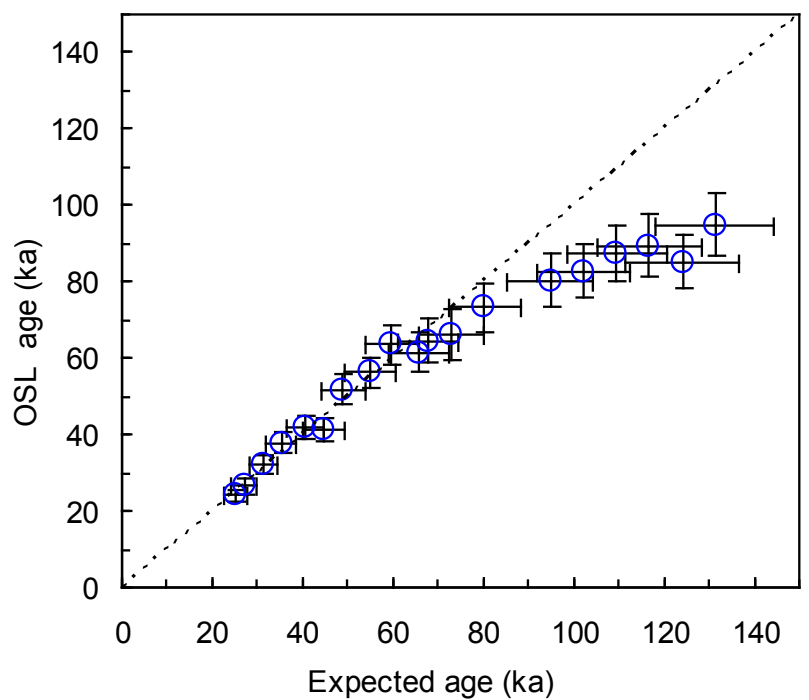

Fig. 1. Plot of OSL ages against expected ages for loess samples from the Chinese Loess Plateau. The OSL ages for the loess samples are from Lai (2010), and their expected ages are inferred from Lu et al. (1999).
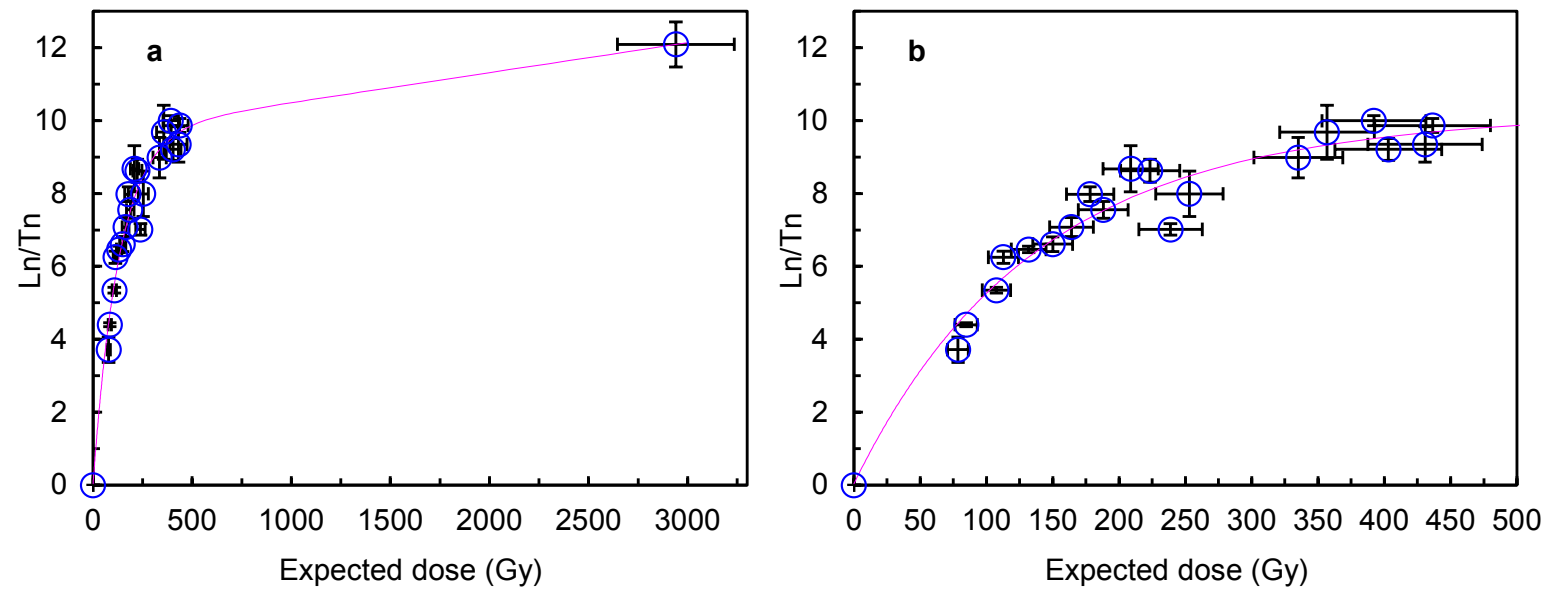

Fig. 2. A growth curve for the loess samples from Chinese Loess Plateau. The curve was constructed by plotting the sensitivity-corrected natural singles $\left(L_{N} / T_{N}\right)$ of the loess samples from different depths of a section against their expected doses calculated from their expected ages and dose rates. (a) For all the samples being dated in Lai (2010), (b) for the samples with expected doses of <450 Gy. 
expected dose (expected age multiplied by dose-rate, see Table 1) and the $\mathrm{Y}$-axis the $\mathrm{L}_{\mathrm{N}} / \mathrm{T}_{\mathrm{N}}$ (mean of four aliquots). The growth curve could be fitted using an exponential plus linear:

$Y=9.63 \cdot(1-\exp (-X / 131))+0.00082 X$

where $\mathrm{D}_{\mathrm{o}}$ is $131 \mathrm{~Gy}$, so that the maximum value for dating should be 262 Gy $\left(2 \mathrm{D}_{\mathrm{o}}\right)$ Gy (corresponding to an OSL age of about $85 \mathrm{ka}$ ), similar to the artificial growth curve by Lai (2010) with a $\mathrm{D}_{\mathrm{o}}$ of 128.3 (Gy).

\section{Anomalous fading test}

To investigate whether anomalous fading is the cause of the age underestimation, three aliquots of each of the four samples (LC12, LC22, LC30, and LM/9) were measured using the procedure described by Auclair et al. (2003). The beta doses applied to those bleached aliquots were 100 and $25 \mathrm{~Gy}$, for $\mathrm{L}_{\mathrm{x}}$ and $\mathrm{T}_{\mathrm{x}}$, respectively. A preheat of $260^{\circ} \mathrm{C}$ for $10 \mathrm{~s}$ was performed immediately after each 100 Gy irradiation. Before measuring the signal corresponding to the test dose, a cut-heat to $220^{\circ} \mathrm{C}$ was used. The OSL measurements were repeated with five different time delays $(0.1,1,10,100$, and $200 \mathrm{~h})$ after irradiation. The normalized OSL signals were plotted versus the time delays (Fig. 3). The g-values are $0.001 \%$, $0.004 \%,-0.004 \%$, and $-0.001 \%$ per decade for samples LC12, LC22, LC30, and LM/9, respectively. The results show that there is no detectable fading for the OSL signals of the four loess samples.
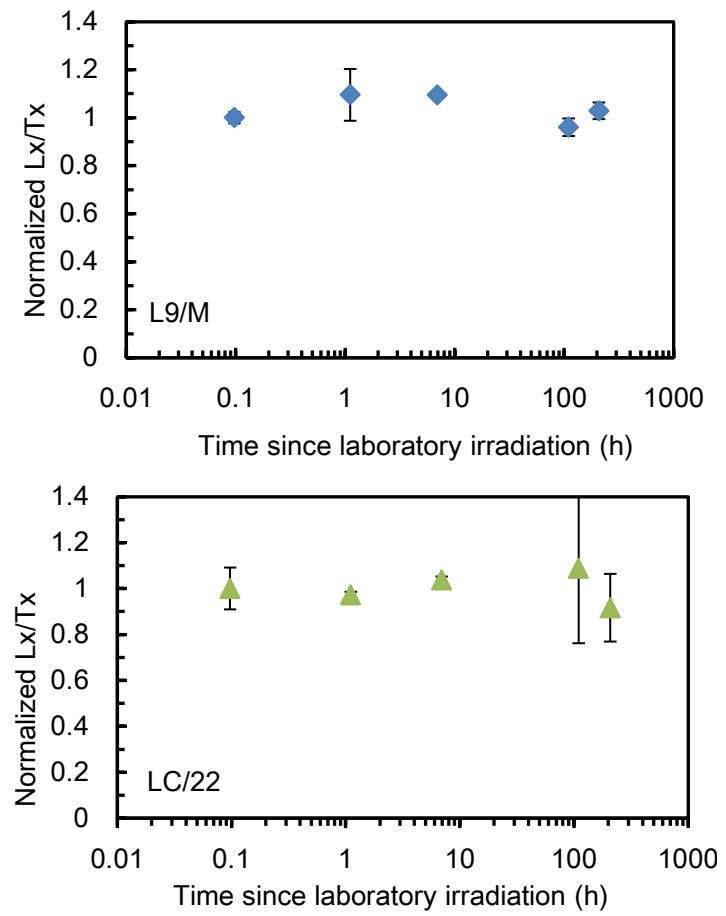

The OSL signals measured in the anomalous fading test were also analyzed using curve-fitting. The bulk OSL signal is dominated by the fast component $(>90 \%)$. The fast component shows no evidence of anomalous fading. The results demonstrate that the OSL age underestimation (Lai, 2010) should not be caused by the anomalous fading of the OSL signals.

\section{Thermal stability of OSL signal: kinetic parameters by pulse annealing}

Pulse annealing experiments were employed to investigate the thermal stability of luminescence signals from quartz ( $\mathrm{Li}$ and Chen, 2001). A previously bleached aliquot was irradiated with $100 \mathrm{~Gy}$, and was heated to a certain temperature. Then the remaining OSL signals $\left(\mathrm{L}_{\mathrm{x}}\right)$ were measured with $40 \mathrm{~s}$ blue stimulation. OSL response at $125^{\circ} \mathrm{C}$ to a test dose of $25 \mathrm{~Gy}$ after $\mathrm{L}_{\mathrm{x}}$ measurement was used to monitor the sensitivity change. At the end of each run, the aliquot was heated to $500^{\circ} \mathrm{C}$ to clean all signals. This run was repeated several times, in which the temperature was increased from 200 to $360^{\circ} \mathrm{C}$, with an increment of $20^{\circ} \mathrm{C}$. The heating rates were $5^{\circ} \mathrm{C} / \mathrm{s}$ for all cycles. At least six aliquots were measured for each of the four samples (LC12, LC22, LC30, and LM/9).

The remnant luminescence after being heated to a certain temperature was displayed as the ratio of the initial values in Fig. 4. The results show that: (1) The normalized OSL signals of sample L9/M showed an early decrease at a lower temperature of $240^{\circ} \mathrm{C}$, comparing with the other three samples (LC/12, LC/22, and LC/30).
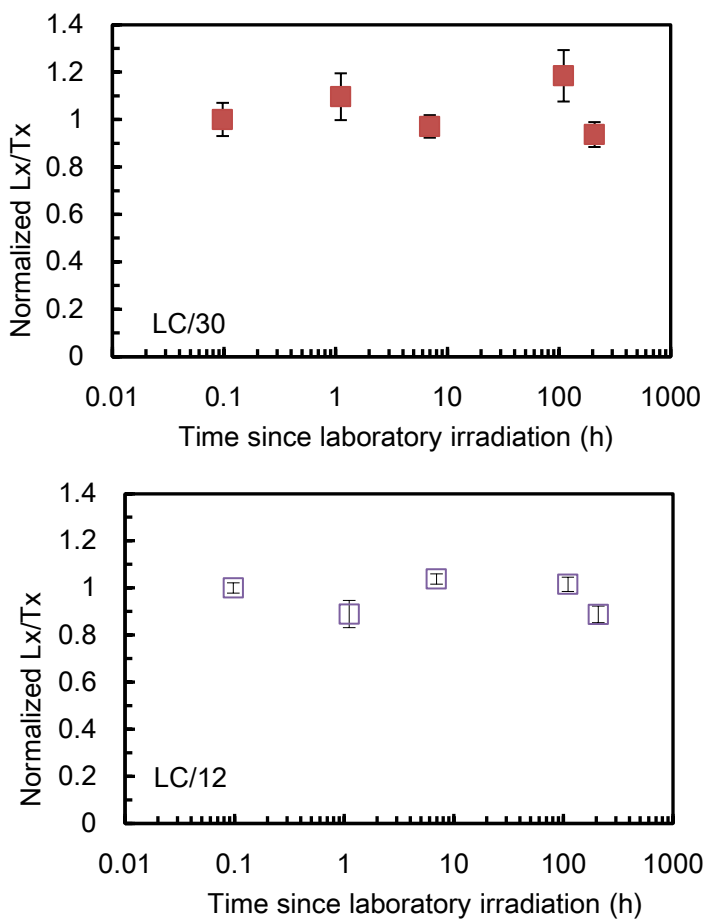

Fig. 3. Dependency of luminescence signals on delay times after irradiation. No anomalous fading was observed. 

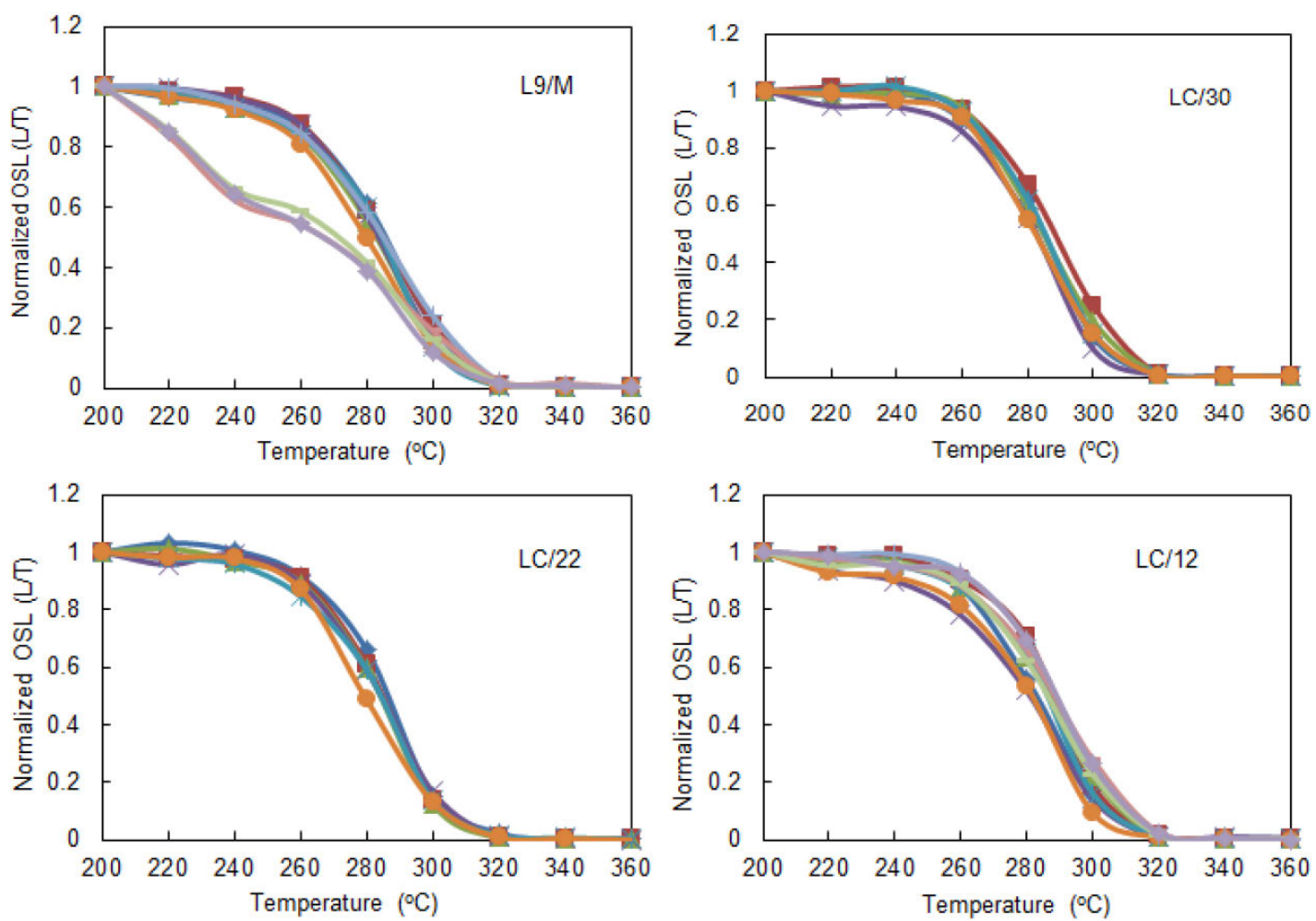

Fig. 4. Pulse annealing curves of the four loess samples ( $L C 12, L C 22, L C 30$, and $L M / 9)$.

(2) The most thermally-unstable signal is observed in only three aliquots of sample L9/M. The curve fitting analysis (as described in Section 4.4) shows that this unstable signal may be related to the ultra-fast component, which could be removed by a preheat at $260^{\circ} \mathrm{C}$ (Jain et al., 2003). (3) Pulse annealing curves of all four samples showed aliquot-toaliquot variations between temperatures ranging from $200^{\circ} \mathrm{C}$ to $300^{\circ} \mathrm{C}$. (4) For all four samples, OSL signals decreased to less than $3 \%$ after heating to $320^{\circ} \mathrm{C}$, suggesting that the OSL signals are mainly from the TL peak of $325^{\circ} \mathrm{C}$ (Wintle and Murray, 1998).

For dating purposes, the lifetime of OSL signal should be at least 5-10 times the age of the sample (Aitken, 1985). Previous studies showed that the quartz OSL signal of sample WIDG8 from Australia is dominated by a stable signal with a lifetime of $850 \mathrm{Ma}$ at $20^{\circ} \mathrm{C}$ (Wintle and Murray, 1998), which is stable enough for dating samples as old as $1 \mathrm{Ma}$. The comparison of the pulse annealing curves for our loess samples and sample WIDG8 shows that the OSL signals from the former is less stable (Fig. 5). The beginning and ending of the OSL signals of the loess samples are $10-20^{\circ} \mathrm{C}$ earlier than those of the OSL signal measured from sample WIDG8. The TL peak corresponding to such signal is thus thermally less stable by $10-20^{\circ} \mathrm{C}$.

To evaluate the effects of the unstable signal on the underestimation of quartz OSL ages, trap parameters, including trap depth (E), frequency factor (s) are obtained

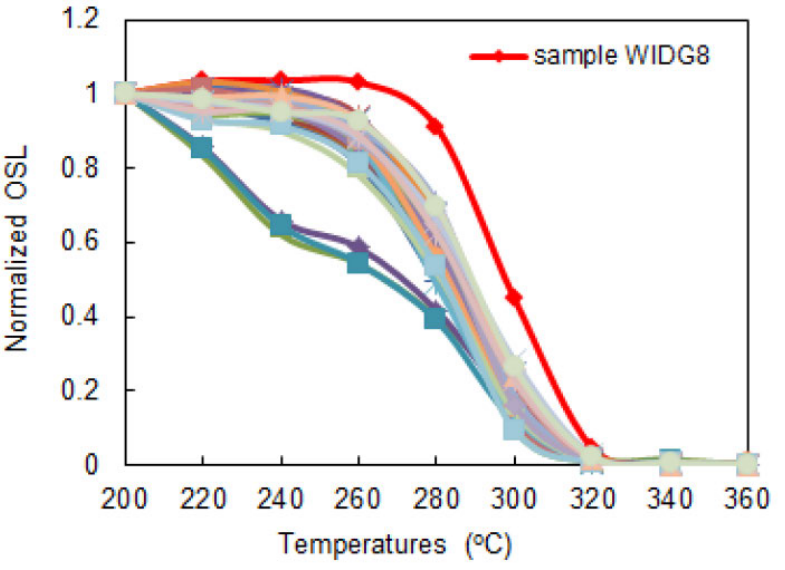

Fig. 5. Comparison of thermal stability between loess samples and a typical quartz sample WIDG8 from Australia used by Murray and Wintle (1999).

based on the fitting of the pulse annealing curves (Singarayer and Bailey, 2003). Assuming first-order kinetics during thermal erosion in the pulse annealing experiments, trap lifetime is derived by equation:

$\tau=s^{-1} \cdot \exp \left(E / k_{\mathrm{B}} T\right)$ 
where $\mathrm{T}$ is temperature given in Kelvin and $\mathrm{k}_{\mathrm{B}}$ is Boltzmann's constant. The remnant trapped charge $\mathrm{n}$ after annealing to temperature $\mathrm{T}$, is

$$
n=n_{0} \exp \left[\begin{array}{l}
\left(\frac{-s k_{B} T^{2}}{B E} \exp \left(-\frac{E}{k T}\right)\right)+ \\
\left(\frac{-s k_{B} T_{0}^{2}}{B E} \exp \left(-\frac{E}{k T_{0}}\right)\right)
\end{array}\right]
$$

where $\mathrm{n}_{0}$ is the initial trapped charge concentration, $\mathrm{T}_{0}$ is the ambient room temperature $(\sim 293 \mathrm{~K})$ (Singarayer, 2002). The obtained trap depth (E), frequency factor (s) for the loess samples are listed in Table 2, and the results of the same parameters by Singarayer and Bailey (2003) and Wintle and Murray (1998) are also listed in Table 2 for comparison. While the lifetime at $20^{\circ} \mathrm{C}$ are $850 \mathrm{Ma}$ by Wintle and Murray (1998) and 310 Ma by Singarayer and Bailey (2003), the lifetime for the loess samples under the study is only $0.311 \mathrm{Ma}$. A calibration quartz sample, provided by Risoe, for calibrating the beta source was also measured and the lifetime is $393 \mathrm{Ma}$. The trap depth (E) of loess samples is also much lower than that of WIDG 8 (Table 2). The calculated value is consistent with the OSL ages measured for loess samples. Considering the fact that the measured OSL age is only $107 \mathrm{ka}$ for sample L9/M with an expected age of $\sim 800 \mathrm{ka}$ (Table 2), the lifetime of the OSL signal from loess quartz should be shorter than $800 \mathrm{ka}$ and probably is around $100 \mathrm{ka}$. The thermal instability might be the reason causing the age underestimation in those loess samples when the quartz OSL signal is used for dating.

\section{Optical properties of the OSL signal}

Curve fitting was then used to 1) determine whether the optical properties of the signals from the loess quartz grains are different from previously reported quartz samples, as well as the thermal stability; 2) to determine the relative contribution of components in the initial bulk OSL signal used for dating (Bailey et al., 1997). At least two exponentially decaying components plus a constant background were needed to fit the CW-OSL curves, described by the equation

Table 2. Trap parameters for loess samples in this study, as well as those from Wintle and Murray (1998) and Singarayer and Bailey (2003) for comparison. The calibration quartz sample was provided by Risoe for the purpose to calibrate the beta source of the OSL machine.

\begin{tabular}{llccc}
\hline References & $\begin{array}{l}\text { Signals } \\
\text { measured }\end{array}$ & $\begin{array}{c}\mathbf{E} \\
(\mathbf{e V})\end{array}$ & $\begin{array}{c}\mathbf{s} \\
\left(\mathbf{1 0 ^ { 1 1 }} \mathbf{s}^{-1}\right)\end{array}$ & $\begin{array}{c}\text { Lifetime at } \\
\mathbf{2 0} \mathbf{C}(\mathbf{M a})\end{array}$ \\
\hline $\begin{array}{l}\text { Singarayer and Bailey } \\
(2003)\end{array}$ & $\begin{array}{l}\text { Fast } \\
\text { component }\end{array}$ & 1.74 & $8.9 \cdot 10^{2}$ & 310 \\
\hline Wintle and Murray (1998) & Bulk OSL & 1.88 & $7.9 \cdot 10^{4}$ & 850 \\
\hline $\begin{array}{l}\text { Calibration quartz } \\
\text { (this study) }\end{array}$ & Bulk OSL & 1.79 & $1.4 \cdot 10^{4}$ & 393 \\
\hline Loess (this study) & Bulk OSL & 1.48 & $5.0 \cdot 10$ & 0.311 \\
\hline
\end{tabular}

$L=A \cdot \exp \left(-b_{1} \cdot t\right)+B \cdot \exp \left(-b_{2} \cdot t\right)+C$

The average value of detrapping probability $b_{1}$ of the fastest component is $3.13 \pm 0.1 \mathrm{~s}^{-1}$ for all OSL curves measured, including both natural signals and regenerative ones from four loess samples. There is no significant change in the component contribution between the natural and regenerative OSL signals. A photoionization crosssection $\alpha$ of $(2.93 \pm 0.10) \cdot 10^{-17} \mathrm{~cm}^{2}$ was obtained. This is consistent with the value for the fast component in previous studies (Jain et al., 2003; Singarayer and Bailey, 2003; Lowick and Preusser, 2011).

Based on the curve fitting, relative contribution of each component in the OSL signals are plotted in Fig. 6. The fast component contributes to over $90 \%$ of the OSL signals measured in the first 0.6 second from the aliquot. The OSL signal from the loess sample is fast-component dominated, confirming the results of Lai (2010).

For three aliquots of sample L9/M, an extra component is required (Fig. 7). The calculated photoionization cross-section $\alpha$ is $2.35 \cdot 10^{-16} \mathrm{~cm}^{2}$, which is consistent with the value of $2.9 \cdot 10^{-16} \mathrm{~cm}^{2}$ obtained for the ultra-fast component (Jain et al., 2003). The ultra-fast component decreases to a negligible level $(<5 \%)$ after being heated to a temperature of $260^{\circ} \mathrm{C}$. Thus, this component would not affect the SAR dating results by Lai (2010), in which a pre-heat step $\left(260^{\circ} \mathrm{C}\right.$ for $\left.10 \mathrm{~s}\right)$ was used before measuring the OSL signals.

\section{CONCLUSIONS}

This study investigated the possible factors affecting the age underestimation, when using the quartz OSLSAR protocol on loess samples from Luochuan section in the Chinese Loess plateau. The growth curves in nature, fading property, thermal stability and optical properties of the quartz OSL have been investigated. The results show

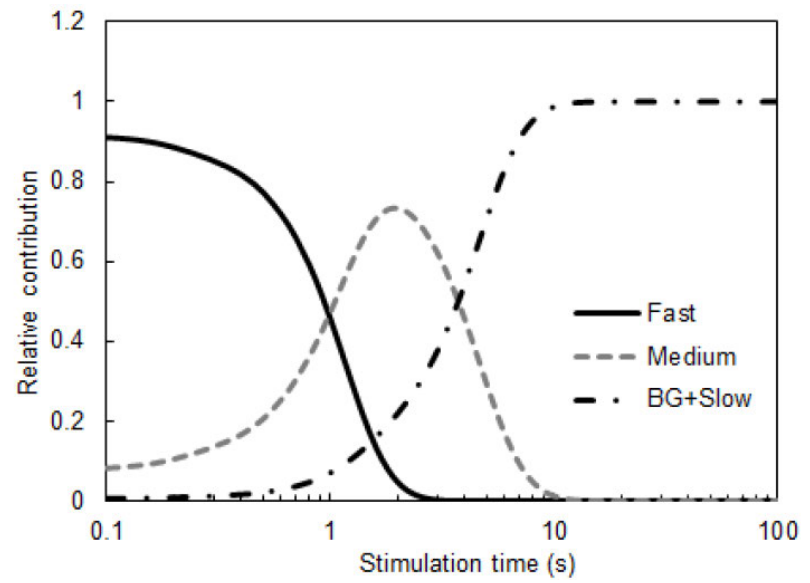

Fig. 6. Relative contribution of components from the OSL signal. The values are based on fitting of one regenerative OSL decaying curve of sample L12. The results are representative for most signals measured except some from sample $L 9 / M$. 


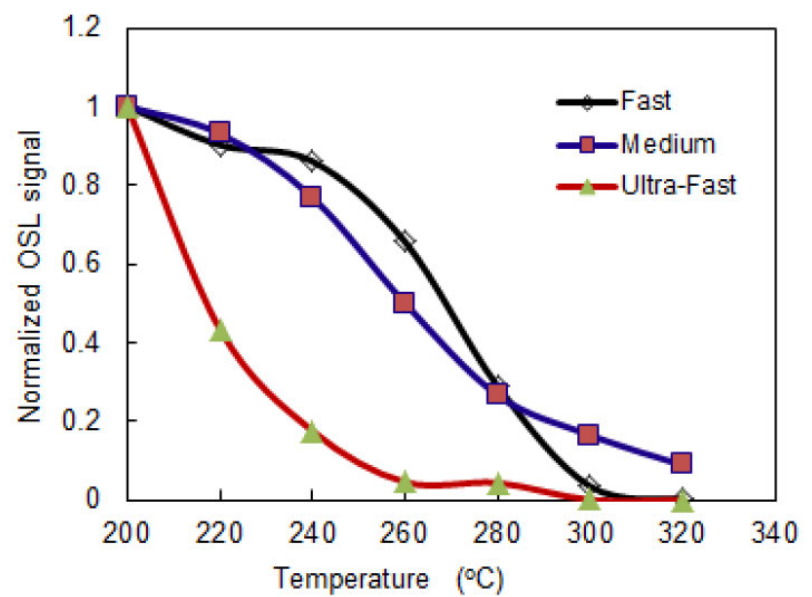

Fig. 7. Pulse annealing curve for the fast, medium and ultra-fast component from Sample L9/M. Signals of all three components are extracted from the CW-OSL curves and are normalized to their initial value.

that (1) the growth curve in nature (via $\mathrm{L}_{\mathrm{N}} / \mathrm{T}_{\mathrm{N}} v s$. expected dose) has a $\mathrm{D}_{\mathrm{o}}$ of $131 \mathrm{~Gy}$, allowing the determination of up to $\sim 262 \mathrm{~Gy}\left(2 \mathrm{D}_{\mathrm{o}}\right)$ (with an OSL age of about $85 \mathrm{ka}$ for loess), and it is similar to the artificial growth curve constructed in the laboratory using the SAR protocol. (2) The OSL is fast component dominated based on curve fitting analysis, and does not fade anomalously through laboratory detection, which means that anomalous fading is not a reason to explain age underestimation. (3) The barrier age of $\sim 100$ ka reported by Lai (2010) is due to the lower than expected signal thermal stability with a life-time of only $0.311 \mathrm{Ma}$ at $20^{\circ} \mathrm{C}$, much lower than previously reported life-time of $>100 \mathrm{Ma}$ for Australian quartz sample WIDG8.

\section{ACKNOWLEDGEMENTS}

This work is supported by China NSF (41172168, 41290252). We thank three anonymous reviewers for constructive comments which improved the paper.

\section{REFERENCES}

Aitken MJ, 1985. Thermoluminescence Dating. Academic Press, London.

Auclair M, Lamothe M and Huot S, 2003. Measurement of anomalous fading for feldspar IRSL using SAR. Radiation Measurements 37(4-5): 487-492, DOI 10.1016/S1350-4487(03)00018-0.

Bailey RM, Smith BW and Rhodes RJ, 1997. Partial bleaching and the decay form characteristics of quartz OSL. Radiation Measurements 27(2): 123-136, DOI 10.1016/S1350-4487(96)00157-6.

Bonde A, Murray AS and Friedrich WL, 2001. Santorini: luminescence dating of a volcanic province using quartz. Quaternary Science Reviews 20(5-9): 789-793, DOI 10.1016/S0277-3791(00)00034-2.

Buylaert JP, Murray AS, Vandenberghe D, Vriend M, De Corte F and Van den haute P, 2008. Optical dating of Chinese loess using sandsized quartz: establishing a time frame for Late Pleistocene climate changes in the western part of the Chinese Loess Plateau. Quater- nary Geochronology 3(1-2): 99-113, DOI 10.1016/j.quageo.2007.05.003.

Chapot MS, Roberts HM, Duller GAT and Lai ZP, 2012. A comparison of natural- and laboratory-generated dose response curves for quartz optically stimulated luminescence signals from Chinese Loess. Radiation Measurements 47(11-12): 1045-1052, DOI 10.1016/j.radmeas.2012.09.001.

Choi JH, Murray AS, Cheong CS, Hong DG and Chang HW, 2003. The resolution of stratigraphic inconsistency in the luminescence ages of marine terrace sediments from Korea. Quaternary Science Reviews 22(10-13): 1201-1206, DOI 10.1016/S0277-3791(03)000222.

Debenham NC, 1985. Use of UV emission in TL dating of sediment. Nuclear Tracks and Radiation Measurements 10(4-6): 717-724, DOI 10.1016/0735-245X(85)90080-8.

Fan AC, Li SH and Li B, 2011. Observation of unstable fast component in OSL of quartz. Radiation Measurements 46(1): 21-28, DOI 10.1016/j.radmeas.2010.10.001.

Kukla G and An Z, 1989. Loess stratigraphy in central China. Palaeogeography, Palaeoclimatology, Palaeoecology 72: 203-225, DOI 10.1016/0031-0182(89)90143-0.

Jain M, Murray AS and Bøtter-Jensen L, 2003. Characterisation of bluelight stimulated luminescence components in different quartz samples: implications for dose measurement. Radiation Measurements 37(4-5): 441-449, DOI 10.1016/S1350-4487(03)00052-0.

Lai ZP, 2010. Chronology and the upper dating limit for loess samples from Luochuan section in the Chinese Loess Plateau using quartz OSL SAR protocol. Journal of Asian Earth Sciences 37(2): 176185, DOI 10.1016/j.jseaes.2009.08.003.

Lamothe M and Auclair M, 1999. A solution to anomalous fading and age shortfalls in optical dating of feldspar minerals. Earth and Planetary Science Letters 171(3): 319-323, DOI 10.1016/S0012821X(99)00180-6.

Li B and Li SH, 2006. Comparison of De estimates using the fast component and the medium component of quartz OSL. Radiation Measurements $\quad 41(2): \quad 125-136, \quad$ DOI 10.1016/j.radmeas.2005.06.037.

Li SH and Chen G, 2001. Studies of thermal stability of trapped charges associated with OSL from quartz. Journal of Physics D: Applied Physics 34(4): 493-498, DOI 10.1088/0022-3727/34/4/309.

Lowick SE, Preusser and Wintle AG, 2010. Investigating quartz optically stimulated luminescence dose-response curves at high doses. Radiation Measurements 45(9): 975-984, DOI 10.1016/j.radmeas.2010.07.010.

Lowick SE and Preusser F, 2011. Investigating age underestimation in the high dose region of optically stimulated luminescence using fine grain quartz. Quaternary Geochronology 6(1): 33-41, DOI 10.1016/j.quageo.2010.08.001

Lu HY, Liu XD, Zhang FQ, An ZS and Dodson J, 1999. Astronomical calibration of loess-paleosol deposits at Luochuan, central Chinese Loess Plateau. Palaeogeography, Palaeoclimatology, Palaeoecology 154(3): 237-246, DOI 10.1016/S0031-0182(99)00113-3.

$\mathrm{Lu}$ YC, Wang XL and Wintle AG, 2007. A new OSL chronology for dust accumulation in the last 130,000 yr for the Chinese Loess Plateau. Quaternary Research 67(1): 152-160, DOI 10.1016/j.yqres.2006.08.003.

Murray AS and Wintle AG, 1999. Isothermal decay of optically stimulated luminescence, Radiation Measurements 30(1): 119-125, DOI 10.1016/S1350-4487(98)00097-3.

Qin JT and Zhou LP, 2009. Stepped-irradiation SAR: A viable approach to circumvent OSL equivalent dose underestimation in last glacial loess of northwestern China. Radiation Measurements 44(5-6): 417-422, DOI 10.1016/j.radmeas.2009.06.008.

Singarayer JS, 2002. Linearly modulated optically stimulated luminescence of sedimentary quartz: physical mechanisms and implications for dating. PhD thesis, University of Oxford, Oxford.

Singarayer JS and Bailey RM, 2003. Further investigations of the quartz optically stimulated luminescence components using linear modulation. Radiation Measurements 37(4-5): 451-458, DOI 10.1016/S1350-4487(03)00062-3. 
Tsukamoto S, Murray AS, Huot S, Watanuki T, Denby PM and BotterJensen L, 2007. Luminescence property of volcanic quartz and the use of red isothermal TL for dating tephras. Radiation Measurements 42(2): 190-197, DOI 10.1016/j.radmeas.2006.07.008.

Watanuki T, Murray AS and Tsukamoto S, 2003. A comparison of OSL ages derived from silt-sized quartz and polymineral grains from Chinese loess. Quaternary Science Reviews 22(10-13): 991-997, DOI 10.1016/S0277-3791(03)00053-2.

Watanuki T, Murray AS and Tsukamoto S, 2005. Quartz and polymineral luminescence dating of Japanese loess over the last 0.6 Ma: Comparison with an independent chronology. Earth and
Planetary Science Letters 240(3-4): 774-789, DOI 10.1016/j.eps1.2005.09.027.

Wintle AG, 1973. Anomalous fading of thermoluminescence in mineral samples. Nature 245(5421): 143-144, DOI 10.1038/245143a0.

Wintle AG and Murray AS, 1998. Towards the development of a preheat procedure for OSL dating of quartz. Radiation Measurements 29(1): 81-94, DOI 10.1016/S1350-4487(97)00228-X.

Wintle AG and Murray AS, 2006. A review of quartz optically stimulated luminescence characteristics and their relevance in singlealiquot regeneration dating protocols. Radiation Measurements 41(4): 369-391, DOI 10.1016/j.radmeas.2005.11.001. 